\title{
Algumas sugestões referentes aos processos das ações de divisão e demarcação de terras
}

\author{
Desembargador João Beltrão de Andrade Lima( $\left.{ }^{*}\right)$
}

I. Cumulação das ações de divisão e demarcação de terras.

0 artigo $20^{\circ}$ do Titulo referente ás ações de divisão e demarcação de terras, da parte do Projeto de Codigo de Processo Civil e Comercial organisado pelo Exmo. Sr. Ministro Artur Ribeiro de Oliveira, permite a cumulação das ações de divisão e demarcação de terras.

Assim dispõe este artigo:

“E' licita a cumulação destas ações, para a exata verificação da área dividenda, devendo ser, preliminarmente, promovida a demarcação total ou parcial do imovel comum, com citação dos confrontantes e intimação dos condominios que poderão defender outra linha perimetrica, se entenderem prejudicial ao condominio a traçada pelo promovente.

( ${ }^{*}$ Representante da Côrte de Apelação do Estado de Mats Grosso no Congresso Nacional de Direito Judiciario. 
$\left.\S 1 .^{\circ}\right)$ Nesta ultima hipotese, o condomino intervirá, como assistente ao promovente, na defesa dos direitos da comunhão.

§ 2:0) Concluidas as linhas da demarcação e homologada esta, definitivamente, proceder-se-á á divisão, considerando-se os confrontantes extranhos ao processo divisorio".

Dos proprios termos deste dispositivo, se depreende que não se trata propriamente dé uma cumulação de ações.

Para serem cumuladas em um mesmo processo, as ações devem obedecer ao mesmo rito processual. Devem ser deduzidas no mesmo libelo, seguir os mesmos tramites processuaes e ser julgadas simultaneamente pela mesma sentença.

No processo cumulativo, instituido neste dispositivo, as duas ações não são simultaneamente julgadas pela mesma sentença. Concluidas as linhas da demarcação, esta será homologada, definitivamente. $\mathrm{E}$, depois de concluida a demarcação pela sua decisão definitiva, proceder-se-á então á divisão, considerando-se os confrontantes extranhos ao processo divisorio.

Acresce ainda que as partes litigantes não ocupam a mesma situação nesse processo comum. Os condominos do imovel dividendo, contra os quaes é promovida a ação de divisão, são reus nesta ação. $\mathrm{E}$, na ação de demarcação, promovida por um outro condomino, cumulativamente com a de divisão, eles tem o direito de intervir, como assistentes do autor. Assim, as mesmas pessoas, num mesmo processo, figuram necessariamente $\mathrm{em}$ posições antagonicas: como assistentes do autor e promovente das duas ações, na qualidade de condomino do imovel demarcando; e como reus, na qualidade de condomino do imovel dividendo. Como reus, defendem os seus direitos, conjuntamente com os outros reus, os confrontantes do imovel demarcando, nos prazos comuns assinados para a contestação e para a treplica; como assistentes do autor, defendem os seus direitos, con- 
juntamente com este, no prazo comum, assinado para a replica da ação.

A anomala situação desses litigantes num mesmo processo e a circumstancia de não serem as duas ações julgadas pela mesma sentença demonstram a impossibilidade de sua cumulação. Na hipotese prevista neste dispositivo, quando os limites do imovel dividendo não forem definidos e incontestes, é aconselhavel que se faça a demarcação judicial desse imovel, antes de promover a respetiva ação de divisão.

Com estas considerações, proponho a substituição do dispositivo em apreço pelo seguinte:

Art. - As ações de divisão e demarcação não poderão ser cumuladas no mesmo processo.

Paragrafo unico - Se os limites do imovel dividendo não forem certos e incontestes, á ação de divisão deverá preceder a de demarcação, total ou parcial, desse imovel, para a constituição ou aviventação dos seus limites".

\section{Liquidação dos direitos dos confrontantes, antes de ultimado o processo de divisão.}

Dispõem os artigos 45,46 e 47 desse Titulo, referente ás divisões e demarcações de terras:

"Art. - Os confrontantes do imovel dividendo são extranhos ao processo divisorio, ficando-lhes salvo, porém, o direito de, por ação competente, pedirem a restituição dos terrenos que julguem lhes haverem sido usurpados por invasão das linhas limitrofes constitutivas do perimetro.

Paragrafo unico - Os socios do imovel, porém, para restabelecer o exato perimetro deste, 
poderão impugnar o traçado, na inicial, pelo promovente, ampliando-o ou restringindo-o".

Art. - A ação dos confrontantes será exercida contra todos os condominos, se intentada antes de passar em julgado a sentença homologatoria da divisão, ou contra os quinhoeiros dos terrenos reclamados, si proposta, posteriormente.

Paragrafo unico - Neste ultimo caso, terão os acionados o direito de, pela mesma sentença, que os obrigar a restituição, haver dos outros condominos, litis-consortes na divisão, ou de seus sucessores a titulo universal, a proporcional composição pecuniaria do desfalque sofrido".

Art. - Se qualquer linha do perimetro apanhar bemfeitorias dos confrontantes, feitas, ha mais de um ano, serão respeitadas, bem como os terrenos respectivos, não sendo computados na avaliação da área do imovel dividendo e ficando salva aos condominos a ação competente para as reivindicar, segundo as forças de seus titulos.

Paragrafo unico - Considerar-se-ão bemfeitorias para os efeitos deste artigo, as edificações, os muros e cercas, os pastos fechados, as culturas de qualquer especie, não abandonados, ha mais de tres anos".

Estas disposições amparam cabalmente os direitos dos confrontantes. Para defesa da sua propriedade sobre os seus terrenos, invadidos pela linha limitrofe, constitutiva do perimetro do imovel dividendo, tem a ação reivindicatoria, que poderão exercitar, a qualquer tempo, antes ou depois que passar em julgado a sentença homologatoria da divisão, contra todos os condominos, na primeira hipotese, ou contra os quinhoeiros dos terrenos reclamados, se já estiver extinto o condominio. Os seus direitos sobre as bemfeitorias serão respeitados, até a decisão definitiva da ação reivindicatoria, quer lhes pertençam os terrenos em que elas assentam, quer 
façam parte do imovel dividendo, quer eles possuam em bôa fé esses terrenos, quer a sua posse se não revista desse requesito.

Não acontece o mesmo, porém, quanto aos direitos dos condominos. O quinhoeiro dos terrenos judicialmente reclamados pelos confrontantes pode ser completamente espoliado, em beneficio dos outros condominos. Já sofre uma diminuição em seus direitos, quando, em compensação do quinhão que lhe tocou e foi judicialmente reivindicado pelo confrontante, a lei lhe dá - "uma ação pessoal contra os outros condominos, litisconsortes na divisão, ou contra os seus sucessores a titulo universal, afim de haver a proporcional composição pecuniaria do desfalque sofrido". E total será o seu prejuizo se, ao tempo da execução dessa ação pessoal, os outros condominos, litis-consortes na divisão, ou os seus successores a titulo universal, estiverem insolvaveis. Assim, esse quinhoeiro, que tinha uma parte no imovel comum, que concorreu para as despezas da divisão desse imovel com uma quota proporcional á sua parte na comunhão, é afinal espoliado em todos os seus direitos, em proveito dos outros condominos.

0 artigo 47, mandando respeitar as bemfeitorias dos confrontantes, feitas ha mais de um ano, bem como os terrenos respectivos, que não serão computados na avaliação do imovel dividendo, resalva aos condominos a competente ação para os reivindicar, segundo as forças dos seus titulos.

Esta solução tem o grande inconveniente de deixar em comum uma parte do condominio. Assim, torna-se necessaria uma nova ação divisoria, acarretando maiores despezas.

Em ambas as hipoteses será muitas vezes preferivel liquidar os direitos dos confrontantes, antes de ultimar a divisão do imovel. Conseguir-se-á esse objetivo com a seguinte disposição:

Art. - Entregues em cartorio, pelo agrimensor, a planta e o memorial descritivo do imovel dividendo, qualquer condomino poderá 
requerer a suspensão do processo divisorio, emquanto pela competente ação de demarcação, total ou parcial, desse imovel, cumulada com a de reivindicação, não forem definitivamente liquidados os direitos dos confrontantes sobre as bemfeitorias e terrenos abrangidos pelas linhas constitutivas do perimetro desse imovel. Depois que passar em julgado a sentença definitiva proferida nessas ações, proseguir-se-á na divisão, tomando-se por base a linha perimetrica julgada definitivamente nessas mesmas ações".

\section{Rateio, entre os condominos, do excesso de area encontrado dentro do perimetro do imovel dividendo}

O Estado, ou um particular, vende um imovel, transferindo ao comprador, no titulo definitivo de dominio, ou na escritura de compra e venda, todo o seu dominio, posse, direito e ações sobre esse imovel. Por força desses titulos, o comprador torna-se o exclusivo proprietario e possuidor de toda a área desse imovel.

O seu direito de dominio e posse tem a mesma amplitude, quer a venda tenha sido feita ad mensuram, quer ad corpus. Na primeira hipotese, feita a venda ad mensuram, estipulado o preço por medida de extensão, se a área verificada exceder á constante do titulo, o comprador, por força desse titulo, adquire toda essa área, não somente a extensão constante do titulo, como o excesso da área verificada, por maior que seja esse excesso, respondendo ao vendedor tão somente pelo suplemento do preço correspondente ao mesmo. Na segunda hipotese, feita a venda ad conpus, - "quando estipulado um preço unico para a totalidade da coisa vendida" - , como define Pedro Lessa essa modalidade do contrato de compra e venda, ou - "si o imovel foi vendido como coisa certa e discriminada, tendo 
sido apenas enunciativa a referencia ás suas dimenções (o que se presume sempre que a diferença entre a dimensão real do imovel e a constante do titulo não exceder da vigesima parte da extensão total enunciada)" - , como é expresso no artigo 1.136 do Codigo Civil, se a área verificada exceder á constante do titulo, o comprador, ainda por força desse titulo, adquire toda essa área, não somente a extensão constante do titulo, como o excesso da área verificado, por maior que seja esse excesso, sem obrigação de pagar ao vendedor um suplemento do preço.

Em qualquer dessas hipoteses, o dominio sobre toda a área compreendida dentro dos limites do imovel vendido pertence exclusivamente ao comprador. Assim era no direito romano, que vigorou no Brasil, como legislação subsidiaria, até a data em que entrou em execução o Codigo Civil; assim é no direito vigente, consoante o disposto no citado artigo 1.136 desse Codigo. 0 dominio e posse do comprador sobre toda essa área nunca sofreu contestação ou impugnação alguma.

Esse direito do comprador trasmite-se aos seus sucessores, universaes ou singulares, com essa mesma amplitude. $\mathrm{E}$ porque assim lhes pertence esse excesso de área, entre eles deve esse excesso ser proporcionalmente rateado.

Em qualquer dessas duas hipoteses, ou a venda tenha sido feito ad mensuram, ou ad corpus, desde a data da alienação, nenhum direito assiste mais ao vendedor sobre o imovel vendido. Se a venda foi feita ad mensuram, o vendedor terá ainda o direito de haver do comprador, ou dos seus sucessores, um suplemento do preço do imovel. Se a venda foi feita ad corpus, nenhum direito mais lhe assiste contra o comprador ou seus sucessores.

$\mathrm{Na}$ primeira hipotese, na venda feita ad mensuram, quando o vendedor tem o direito de haver do comprador, ou dos seus sucessores, um suplemento do preço do imovel, serve de base para essa indenisação o preço de unidade de superficie, estipulado na escritura de compra e venda, ou no titulo definitivo de dominio expedido ao comprador pelo 
Estado: assim, se o imovel foi vendido á razão de dez mil reis o hectare, verificado um excesso de área de dois mil hectares, o comprador satisfará cabalmente a sua obrigação, pagando ao vendedor a quantia precisa de vinte contos de reis.

Pouco importa que o imovel em apreço, após a sua alienação, tenha se valorisado, ou se desvalorisado; que tenha aumentado, ou tenha diminuido o preço das terras devolutas. A valorisação ou depreciação do imovel não autorisa o vendedor a exigir mais, nem o comprador a pagar quantia inferior ao preço estipulado no titulo definitivo de dominio.

Esse direito do vendedor é um direito pessoal, sujeito a prescrição de trinta anos, prevista no artigo 177 do Codigo Civil, aplicavel a todos os direitos e obrigações pessoaes, para os quaes a lei não tenha estipulado menor prazo.

0 artigo 51 do Titulo do Projeto de Codigo do Processo Civil e Comercial, referente ás divisões e demarcações de terras, prescrevendo que - " $O$ agrimensor organisará o calculo para o orçamento da divisão, rateando entre todos os socios a diferença encontrada no confronto da medição feita e a extensão superficial verificada quando a comunhão se constituio" -, faz expressa referencia aos direitos dos condominos sobre esse excesso de área; silenciando, porém, quanto aos direitos do alienante. Seria aconselhavel a inserção nesse Titulo, em substituição ao referido artigo 51 , da seguinte disposição, em que ficam melhor acentuados os direitos dos condominos e expressamente resalvados os do alienante:

Art. - Praticadas pelos peritos as investigações e operações necessarias para a distribuição equitativa dos quinhões entre os socios, o agrimensor organisará o calculo para o orçamento da divisão, rateando entre todos a diferença encontrada no confronto da área real do imovel, verificada na medição feita neste processo divi- 
sorio, com a extensão superficial do mesmo, constante do respectivo titulo definitivo de dominio, ou da escritura publica de transferencia de dominio sobre esse imovel, pondo em relação as quantidades arimeticas constantes dos titulos com a avaliação do imovel na divisão processada, na hipotese de terem os condominos simples partes ideais do mesmo imovel, originadas de partilhas em inventario ou de outros titulos. Fica salvo ao alienante o direito, que porventura lhe assiste, de haver de cada um dos condominos, ou dos seus sucessores universaes, na proporção dos respectivos quinhões, a quota parte do preço correspondente ao excesso de área calculada de acôrdo com o preço constante desses titulos, ou tabela de preços dos terrenos devolutos vigente ao tempo em que esses titulos foram expedidos; podendo fazer efetivo esse seu direito, em qualquer tempo, emquanto ele não prescrever.

\section{Apuração dos direitos de todos os condominos na primeira fase do processo divisorio.}

Na nota 282 ao artigo 42 do Titulo do Projeto de Codigo do Processo Civil e Comercial, referente ás ações de divisão e demarcação de terras, o Exmo. Sr. Ministro Artur Ribeiro transcreve uma sugestão do eminente professor Francisco Morato, sobre a necessidade de liquidar os direitos de todos os condominos na primeira fase do processo divisorio.

0 professor Francisco Morato assim se expressa sobre a imperiosa necessidade dessa reforma:

"Lembro uma reforma da mais palpitante importancia, pela qual tenho propugnado com aqueles que, na pratica diuturna e assidua da divisão de terras, reclamam contra um desacerto 
capital do Decreto n. 720 de 1890 e dos Codigos estaduaes que o têm copiado.

0 Decreto n. 720 conjugou em uma só instancia a fase contenciosa e a fase executoria da communi dividundo, tornando desnecessario o antigo desdobramento em duas ações: - uma, a ação de carater em principio litigioso, em que se fixa a questão da propriedade, isto é, em que se apuram quaes os condominos, quaes os seus titulos e qual a quota abstrata de condominio de cada um; outra, a de carater administrativo, em que se concretisam as quotas ideaes dos condividentes, e, para isso, se procede ás necessarias operações topograficas, sem mais indagação sobre o dominio e a extensão do dominio de cada qual.

Sempre se entendeu que a segunda ação não comporta questão de dominio, nem de dominio na substancia nem de dominio na extensão, quer dizer, nem da existencia do titulo de dominio, nem da força ou quantidade desse titulo; a qual questão deve ser resolvida e assentada na primeira ação.

O direito romano era de clareza irresistivel: as partes entravam na partilha geodesica, que tal era a função da communi dividundo, com seus direitos reconhecidos na existencia e na qualidade. L'actio communi dividundo, presuppone, adunque, che sia pacifico tra le parti que ciascuna ha um diritto de communione e per qual parte. (Glücle, Pandectas, § 736, nota c).

No emtanto, o Dec. n. 720 e os codigos estaduaes, jungindo a primeira ação á segunda, sob o nome de fases, mandam verificar e conferir os titulos na segunda: na segunda é que se apuram os titulos e que o juiz delibera contempla-los e com que força na partilha.

O que tudo é causa das mais disparatadas e deploraveis consequencias. 
Muitas vezes um condomino vê a sua propriedade cerceada ou negada na segunda fase, e, por isso, ou é enormemente lesado, ou excluido da divisão, sem que possa debater e instruir os seus direitos.

O promovente aponta-me como um dos condominos promovidos. Nada tenho que debater na fase litigiosa, pois o meu direito não é contestado. Entro na fase executoria, e então sou excluido, ou tenho o meu direito horrivelmente decepado por provocação do promovente, dos promovidos ou do agrimensor, que é quem, na verdade, apura os titulos com o promovente.

Não posso discutir; a lei não admite. Sou excluido. Só me é dado apelar, mas a apelação não é juizo de instrução, de sorte que sou forçado a ver o meu direito diminuido sem provas em plenario. Apelo, mas a apelação só é recebida no efeito devolutivo; de modo que, si tenho sitio e bemfeitorias no imovel dividendo, sou coagido a ver meus adversarios se intrusarem naquele e nestas, sem, nem ao menos, darem fiança do que é meu!

Não é possivel que estas cousas não choquem as sentimentos dos juristas.

Propunha, pois, que retornassemos á sabedoria romana, obrigando o promovente a relacionar os condominos e a extensão do dominio de cada um.

Se não houver contestação sobre este ponto, o juiz julga procedente a ação, conforme o pedido e a justiça que merecer. E está já apurado o dominio, nos seus titulares e na força dos titulos de cada um.

Se ha contestação, a sentença decide, como fôr de direito; e a cousa está apurada do mesmo geito. 
Não se diga que isto dificulta a ação. Se dificulta para o promovente, a mesma dificuldade perdura para o apurador de titulos e em uma ocasião em que a parte não tem mais a palavra.

Não se diga que isso possa prejudicar a terceiros, que estariam expostos aos mesmos perigos pelo sistema atual. Ailás, a sentença não aproveita, nem empece mais que ás pessoas entre que é dada".

Comentando essa sugestão, o Ministro Artur Ribeiro declara que "segundo lhe parece, o professor Francisco Morato não dá a sua valiosa adhesão á orientação impressa pelo Decreto n. 720 ao juizo divisorio, em o nosso direito, o que permitiu se conjugasse em a mesma instancia a face contenciosa e a fase executoria da Communi dividundo actio. "Confessa" não conhecer nenhum caso, antes daquele Decreto, em que se agitasse, perante os nossos tribunaes, a ação previa para a fixação da propriedade no condominio, como um preparatorio da Communi dividundo propriamente dita". Recorda que "no direito anterior áquele Decreto, o processo divisorio era muito complicado e embaraçoso, um verdadeiro engrimanço cheio de confusão, em que se entrelaçavam o arbitrio do juiz e dos tecnicos e a deficiencia e a quasi inexistencia de titulos dos socios". Afirma que "não se pode contestar que o Decreto n. 720 tenha melhorado consideravelmente esse estado de cousas, ordenando, simplificando e metodisando o processo divisorio e dando-nos assim um terreno mais firme, para avançarmos nos meandros da nossa propriedade rural, incerta e de origem quasi sempre obscura".

Mas, reconhece "a inteira procedencia das observações do eminente professor sobre a necessidade da divisão, com o seu direito inteiramente limpo de duvidas, eliminadas na primeira fase do processo". E, com essa finalidade, inseriu no artigo 42 desse Titulo o seu quarto inciso, em que se exige que a petição inicial da ação de divisão contenha "a exten- 
são do dominio de cada um dos condominos, ao menos aproximadamente, se os titulos não forem conhecidos".

São incontestaveis as vantagens do Decreto n. 720 sobre a legislação e praxes anteriores, pelas quaes se regulava o processo das divisões de terras. Mas, entre os seus grandes meritos, não se pode infelizmente incluir o de ter satisfeito a imperiosa necessidade, apontada pelo professor Francisco Mórato.

A providencia sugerida pelo Ministro Artur Ribeiro, embora represente um grande melhoramento introduzido no processo, tambem não satisfaz cabalmente essa necessidade. Em muitos casos, o promovente não poderá satisfazer esse requisito legal: não terá elementos para afirmar, ao menos aproximadamente, qual a extensão do dominio de cada um dos condominos. E não basta que o promovente declare quaes são os condominos do imovel dividendo, quaes os seus titulos e qual a quota abstrata de cada um deles no condominio. $O$ que é imprescindivel é que esses pontos não fiquem apenas esclarecidos, mas definitivamente decididos na fase litigiosa do processo divisorio.

Conseguir-se-ia esse objetivo, imprimindo ao processo divisorio, nessa primeira fase, um rito analogo ao do concurso de credores nas execuções civeis, afim de apurar, antes de iniciada a fase executoria, quaes são os condominos, quaes os seus titulos e qual a parte abstrata que a cada um deles compete no condominio. A fase contenciosa deverá ser processada ordinariamente.

$\mathrm{Na}$ petição inicial, instruida com o seu titulo de dominio, o promovente, além dos outros requesitos enumerados no correspondente artigo do projeto, deverá declarar: a) se os terrenos compreendidos dentro do perimetro do imovel dividendo são todos de uma mesma categoria, ou de categorias diferentes; b) qual o valor, por hectare, desses terrenos, ou dos terrenos compreendidos em cada uma dessas categorias; c) as bemfeitorias comuns existentes no imovel dividendo, com os seus valores; d) qual a quota abstrata que lhe compete nesse imovel; e) a situação 
de sua morada e das suas bemfeitorias nesse imovel; f) a indicação precisa do logar em que pretende que seja localisado o seu quinhão no imovel.

No prazo de dez dias, que lhes será assinado para a contestação, os promovidos, juntando os seus titulos de dominio, deverão igualmente declarar: - a) qual a qucta abstrata que lhes compete no imovel dividendo; b) a situação de suas moradas e bemfeitorias nesse imovel; c) a indicação precisa do logar em que pretendem que sejam localisados os seus quinhões no imovel.

No prazo de dez dias, que lhe será concedido para a replica da ação, o promovente poderá impugnar as declarações e titulos apresentados pelos promovidos.

Cada um dos promovidos, no prazo comum de dez dias, que lhes será concedido para a treplica, poderá por sua vez impugnar as declarações e titulos apresentados pelo promovente e pelos outros promovidos.

$\mathrm{Na}$ dilação probatoria de vinte dias, promovente e promovidos deverão fazer a prova das suas alegações.

Depois das razões finaes, selados e preparados os autos, serão estes conclusos para a sentença definitiva.

A sentença definitiva, que mandar que se proceda á divisão, ponderando as alegações contraditorias das partes e atendendo quanto possivel ás suas justas pretenções, decidirá : quaes são os condominos; qual a parte abstrata desse imovel que compete a cada um deles; o valor, por hectare, dos terrenos constitutivos do imovel, considerado em sua integridade, se a homogeneidade das terras não determinar variedade de preços, ou de cada uma das categorias de terras compreendidas nesse imovel; o valor das bemfeitorias comuns, existentes no mesmo; os logares em que deverão ser localisados os quinhões de cada um desses condominos e a indicação das bemfeitorias comuns que lhes deverão ser adjudicadas.

Somente depois que essa sentença passar definitivamente em julgado é que se dará inicio á fase executoria da 
divisão, na qual não poderão ser novamente ventiladas essas questões decididas na sua fase litigiosa.

\section{Simplificação da fase executoria da divisão.}

Segundo o projeto do eminente Sr. Ministro Artur Ribeiro, a fase executoria do processo de divisão se desdobra em cinco partes distintas.

A primeira parte compreende os trabalhos preliminares para o inicio da divisão. Nessa parte, dentro de um prazo comum de 5 dias, os condominos deverão oferecer os seus titulos, testemunhas e quaesquer documentos que possam esclarecer os peritos sobre a confinação do imovel e constituição do pagamento de cada socio. Findo esse praso, o juiz, por despacho dos autos, designa o dia para o começo da divisão, intimadas as partes e peritos. O agrimensor, á vista dos titulos e de informações das testemunhas, procederá no imovel ás diligencias necessarias para a verificação do ponto de partida para a medição do perimetro do imovel dividendo, apresentando ao juiz um relatorio cir. cumstanciado a respeito e dando o seu parecer motivado. Entregue esse relatorio, pelo agrimensor, em cartorio, o juiz procederá, em audiencia especial, na séde do juizo, com intimação das partes: - a) ao exame e conferencia dos seus titulos; b) á determinação do ponto de partida, fundamentando a sua decisão, caso divirja do parecer do agrimensor.

A segunda parte compreende todos os trabalhos tecnicos para a organisação do memorial descritivo e levantamento da planta do imovel dividendo, desde o reconhecimento do ponto de partida e assentamento do marco primordial. Termina com a entrega, em cartorio, pelo agrimensor, da planta do imovel, acompanhada do memorial descritivo e caderneta das operações de campo.

A terceira parte compreende: - a) o exame, classificação e avaliação das terras; b) o calculo das áreas de 
cada gleba; c) o laudo dos arbitradores sobre a forma da divisão e instituição das servidões que julgarem necessarias; d) audiencia dos interessados sobre o plano da divisão apresentado pelos arbitradores; e) despacho do juiz mandando que se proceda á partilha geodesica do imovel.

A quarta parte se desenvolve no imovel dividendo, com a presença do Juizo na situação desse imovel, se o valor deste exceder de dez contos de reis e fôr a diligencia imprescindivel para ser resolvida qualquer questão entre os socios. Compreende todas as investigações e operações geodesicas e topograficas necessarias para a equitativa distribuição dos quinhões entre os condominos. Termina pelo lançamento nos autos do auto de orçamento e folhas de pagamento dos socios e complemento da planta do imovel pelo assinalamento das linhas divisorias de cada quinhão.

A quinta e ultima parte se desenvolve na séde do juizo, compreendendo a audiencia das partes sobre o processo divisorio e a sentença homologatoria da divisão.

Reconhecido, pela decisão definitiva, proferida na fase contenciosa, quaes são os condominos do imovel e qual a quota abstrata que a cada um deles compete no condominio e deliberada a partilha geodesica do imovel, com a indicação precisa das terras e bemfeitorias que lhes devem tocar, simplifica-se extraordinariamente a fase executoria.

Estando feitas e definitivamente julgadas a classificação e avaliação das terras compreendidas no imovel dividendo, bem como o plano da divisão e instituição das servidões, torna-se desnecessaria a intervenção de arbitradores no processo divisorio.

A função dos arbitradores consiste apenas no seguinte: - a) no exame, classificação e avaliação das terras; b) na organisação do plano da divisão e instituição das servidões.

Mas, em regra, eles limitam-se a assinar os dois laudos, referentes a esses serviços, feitos pelo proprio agrimensor, ou pelo advogado do promovente.

A intervenção dos arbitradores nas divisões, bem como nas demarcações de terras, sómente serve para encarecer 
esses serviços, em detrimentos das partes. Não têm honorarios fixos, mas têm metade dos emolumentos taxados para os juizes por diligencia e estada, e os que se contam aos avaliadores e partidores pelas avaliações e partilhas que fizerem. E nesses emolumentos são consumidas inutilmente fortes somas.

Desnecessaria se torna tambem a presença do juizo no imovel dividendo. Solvidas, na fase contenciosa, todas as questões suscitadas entre os condominos, simplifica-se extraordinariamente a função do agrimensor.

Se ele se não afastar dos termos precisos da sentença exequenda, o seu procedimento não poderá suscitar reclamações rasoaveis.

Se, afastando-se dessa sentença, ferir direitos de qualquer dos condominos, cumprirá a este reclamar contra o procedimento do agrimensor, no prazo que lhe é assinado para dizer sobre os trabalhos tecnicos. Se esse condomino o requerer, poderá o juiz determinar uma vistoria no imovel. Provada a procedencia da reclamação, o agrimensor deverá corrigir o seu erro e pagar as despezas desse incidente. No caso contrario, deverá paga-las exclusivamente o reclamante. Em hipotese alguma, taes despesas deverão ser rateadas entre todos os condominos.

Sendo desnecessarias a intervenção dos arbitradores nos processos divisorios e as diligencias do juizo no imovel dividendo, todos os trabalhos tecnicos deverão ser confiados exclusivamente ao agrimensor.

$\mathrm{E}$ todos esses trabalhos, desde a determinação do ponto de partida da medição, até a medição e demarcação de todos os quinhões, deverão ser feitos de uma assentada.

A fase executoria da divisão poderá desdobrar-se apenas em tres periodos distintos.

O primeiro se desenvolverá na séde do juizo e consistirá na escolha de um agrimensor, que execute, sob sua exclusiva responsabilidade, todos os trabalhos tecnicos da diøisão. Começará pela intimação de todos os condominos para tomarem parte nessa escolha e terminará pela designa- 
ção do dia para o inicio dos trabalhos tecnicos da divisão. Sendo a citação inicial da ação geral e compreensiva da execução, a intimação dos condominos, nesse e em todos os outros termos da execução, poderá ser feita na pessoa dos seus procuradores, ou mediante pregão em audiencia, quando as partes não tivçrem procuradores ou estes não forem encontrados na séde do juizo.

O segundo periodo compreenderá todos os trabalhos tecnicos, desde a determinação do ponto de partida para a medição do perimetro do imovel dividendo até a entrega, em cartorio, feita pelo agrimensor, da planta desse imovel, acompanhada do completo relatorio ou memorial dos trabalhos tecnicos e respectiva caderneta das operações de campo.

O terceiro periodo se desenvolverá na séde do juizo, compreendendo a audiencia das partes sobre os trabalhos tecnicos da divisão e a sentença homologatoria da divisão.

Dispensada a intervenção absolutamente inutil dos arbitradores e as dispendiosas e desnecessarias diligencias do juizo no imovel dividendo, o processo divisorio tornar-se-á mais simples e menos dispendioso.

Conseguir-se-á esse objetivo, substituindo pelos seguintes dispositivos as correspondentes disposições do Titulo em apreço, referentes ao processo das divisões de terras:

Art. - Passada em julgado a sentença definitiva, mandando que se proceda á divisão, serão intimados todos os condominos, nas pessoas dos seus procuradores, ou mediante pregão em audiencia, quando não tiverem procuradores, cu estes não forem encontrados na séde do Juizo, para a escolha de um agrimensor, que execute todos os trabalhos tecnicos de divisâo, sob a sua exclusiva responsabilidade.

Art. - Na audiencia, em que forem acusados essas citaçõcs, proceder-se-á á escolha do agrimensor.

Se todos os condominos presentes indicarem um mesmo profissional, o juiz homologará a escolha das partes.

Se forem diversos os indicados, o juiz nomeará para servir de agrimensor o profissional que fôr indicado pela 
maioria. A maioria será calculada, não pelo numero de condominos, sinão pelo valor dos quinhões.

Havendo empate, decidirá a sorte. A deliberação dos presentes á louvação obrigará os ausentes.

Art. - Compromissado o agrimensor, serão os autos conclusos ao juiz, que designará o dia para o inicio da divisão. Desse despacho serão intimados todos os condominos e o agrimensor.

Art. - No dia designado, o agrimensor dará inicio aos trabalhos tecnicos da divisão.

Tendo em vista a sentença definitiva, que mandou proceder á divisão, e os esclarecimentos que julgar necessarios e lhe forem prestados por testemunhas e visinhos, o agrimensor: - a) determinará e assinalará o ponto de partida para a medição do perimetro do imovel dividendo; b) procederá á medição de todo esse perimetro; c) calculará a extensão superficial desse imovel; d) fará o calculo das áreas classificadas, quando as terras compreendidas dentro dos limites desse imovel não forem todas da mesma natureza ou categoria; e) procederá ás investigações e operações necessarias para a equitativa distribuição dos quinhões entre os condominos e organisará o calculo para a partilha geodesica do imovel, rateando entre todos a diferença encontrada no confronto da medição feita e a extensão superficial verificada quando a comunhão se constituio, pondo em relação as quantidades arimeticas constantes dos titulos com a avaliação do imovel na divisão processada, na hipotese de terem os condominos simples partes ideaes no mesmo imovel, originadas de partilhas em inventarios ou de outros titulos; f) procederá, finalmente, ás operações geodesicas e topograficas, concernentes á separação, medição e demarcação dos quinhões de cada um dos condominos.

Art. - Terminados os trabalhos de campo, o agrimensor fará o levantamento da planta do imovel dividendo e organisará o memorial discritivo da divisão.

Art. - O levantamento das plantas obedecerá ás seguintes regras: 
1. A) As plantas serão levantadas mediante goniometros, ou instrumentos de mais precisão, independentemente de bussola.

2. ${ }^{a}$ ) Serão orientadas segundo o meridiano verdadeiro do logar, determinada a declinação magnetica.

3. A) Além dos pontos de referencia necessarios para as verificações ulteriores, fixar-se-ão marcos especiaes de referencia, orientados e ligados a pontos certos e estaveis, nas sédes das propriedades, mediante os quaes a planta possa incorporar-se depois á carta geral cadastral.

Art. - As plantas conterão, mediante notações convenientes:

1..$^{\circ}$ As altitudes relativas de cada estação do instrumento e a conformação altimetrica ou orografica aproximativa dos terrenos.

2..$^{\circ}$ As construções existentes com a indicação dos seus fins.

3..$^{\circ}$ As valas, cercas e muros divisorios.

4. ${ }^{\circ}$ As aguas principaes que banharem o imovel, determinando-se, quanto se possa, os volumes reduzidos á maxima seca, em termos de se lhes poder calcular o valor mecanico.

5. ) A indicação, mediante côres convencionaes, das culturas existentes, dos pastos, matas, capoeiras.

6. ) As divisas do imovel e de todos os quinhões dos condominos.

Art. - As escalas das plantas poderão variar entre os limites $1.500 \mathrm{~m} 1.500$ e $1.5 .000 \mathrm{~m} \mathrm{1.5.000,} \mathrm{conforme} \mathrm{a} \mathrm{ex-}$ tensão das propriedades rurais. Admitir-se-á a escala de 1.10.000 nas propriedades de mais de cinco quilometros quadrados.

Art. - As plantas trarão anexas a si, autenticadas pelo agrimensor, que as assinará, as cadernetas das operações de campo e o memorial descritivo da medição, indicando:

1.') O ponto de partida da medição, os rumos seguidos, a aviventação dos rumos antigos, com os respectivos calculos.

2. ) Os acidentes encontrados, as cercas, valas, marcos antigos, corregos, rios, lagoas, etc. 
$3 .^{\circ}$ Minuciosamente, os novos marcos assentados, sendo obrigatoria a cravação na estação inicial e nos vertices dos angulos, salvo se algum desses ultimos pontos fôr assinalado por acidentes de dificil remoção ou destruição.

4..$^{\circ}$ As culturas existentes e a sua produção anual.

5. ) A composição geologica dos terrenos, as novas culturas a que possam adatar-se e bem assim a qualidade e extensão dos campos, matas e capoeiras existentes.

6..$^{\circ}$ As industrias agricolas, pastoris, fabris e extrativas, exploradas, ou suscetiveis de exploração.

7.') As vias de comunicação existentes e as que convenha estabelecer.

8. ) As distancias á estação de estrada de ferro, portos de embarque e mercados mais proximos.

9.') O numero conhecido de trabalhadores, empregados na lavoura, com indicação, podendo ser, de suas nacionalidades.

10..$^{\circ}$ O sistema adotado em relação ao serviço agricola e ao estabelecimento de colonos (parceria, salario, subdivisão da propriedade em lotes, empreitadas, etc.).

11. ) Avaliação de todos os moveis e imoveis, descriminando-se os preços de cada um.

12. ) Quaesquer outras informações que possam concorrer para o conhecimento cabal da propriedade e seu valor.

Art. - Além desses requisitos, constarão ainda do memorial descritivo:

1..$^{\circ}$ A confinação e a extensão superficial do imovel.

2..$^{\circ}$ A classificação das terras, com o calculo das áreas de cada sorte e a respectiva avaliação; ou a avaliação do imovel, em sua integridade, quando a homogeneidade das terras não determinar variadade de preços.

3. ) A quantidade geometrica que cabe a cada condomino nas terras dividendas, declarando-se quaes as reduções e compensações proporcionaes feitas em razão da diversidade de preços das glebas componentes de cada quinhão. 
4..$^{\circ}$ As folhas de pagamento de cada condomino, nas quaes serão descritas com precisão as linhas e rumos divisorios, declarados os marcos que foram cravados ou assinalados, mencionadas as bemfeitorias e plantações compreendidas na gleba descriminada, não só as do proprio quinhoeiro, como as que lhe foram adjudicadas, por serem comuns, ou mediante compensação. Na mesma folha de pagamento serão declaradas as servidões que foram instituidas sobre o quinhão demarcado, ou a favor dele, designando-se o logar da servidão e regulando-se o modo e as condições do seu exercicio.

Art. - Entregues em cartorio, pelo agrimensor, a planta, o memorial descritivo da medição e a caderneta das operações de campo, o escrivão junta-los-á aos autos e fará conclusão destes ao juiz, que mandará dar vista ás partes, para dizerem de fato e de direito sobre o processado. 0 promovente terá o praso de dez dias e igual prazo terão em comum todos os promovidos.

Art. - Se alguma das partes reclamar contra o procedimento do agrimensor, por ter este desobedecido á sentença exequenda e prejudicado os seus direitos, o juiz decidirá previamente esse incidente, mandando que o agrimensor proceda ás necessarias retificações, se lhe parecer procedente e provada a reclamação.

Se o reclamante o requerer e ao juiz parecer indispensavel essa diligencia para a solução da reclamação, este mandará que se proceda a uma vistoria.

Se a reclamação fôr julgada procedente o agrimensor pagará todas as despezas do incidente e fará á sua custa a retificação ordenada pelo Juiz. Julgada improcedente a reclamação, exclusivamente ao requerente competirá o pagamento das custas desse incidente.

Art. - Ouvidas as partes e preliminarmente decididas as suas reclamações, selados e preparados os autos, o juiz proferirá a sua sentença, homologando, ou não, a divisão. 


\section{Simplificação da fase executoria nas ações de de= marcação.}

A simplificação da fase executoria das demarcações justifica-se plenamente, pela propria natureza desta ação.

Executados os casos em que as partes recorrem ao processo amigavel de demarcação para deslindar duvidas existentes quanto aos limites de suas propriedades, a ação de demarcação é por sua natureza contenciosa. Os direitos das partes, demarcante e confrontantes, são contraditoriamente ventilados e discutidos na primeira fase desta ação. E a sentença nela proferida tem a autoridade de coisa julgada para todos os interessados que nela intervieram, como autores, como réus, ou como assistentes de uns ou de outros.

Mais ainda do que no processo divisorio, torna-se desnecessaria a intervenção de arbitradores na fase executoria da demarcação e principalmente a presença do juizo no imovel demarcando. Todos os trabalhos tecnicos poderão ser confiados exclusivamente ao profissional que as partes escolherem para servir de agrimensor.

A função do agrimensor é muito simples: executar a sentença definitiva, que poz termo á fase contenciosa da demarcação. Se o agrimensor cingir-se a essa sentença, nenhuma objeção justa poderão suscitar os seus trabalhos. Se, afastando-se dessa sentença, penetrar em terras do imovel demarcando ou nas propriedades limitrofes, que reclame contra o seu procedimento a parte prejudicada.

Se o reclamante pedir uma vistoria, para comprovar a sua reclamação, o juiz deverá deferir o seu requerimento. As despezas desse incidente deverão correr por conta do reclamante, se a sua reclamação fôr improcedente, ou por conta do agrimensor, se este, afastando-se da sentença, der causa á reclamação. E nunca pelos outros interessados, que não concorreram para esse acrescimo de despesas.

Como nas divisões, a escolha do agrimensor deverá ser feita no inicio dessa segunda fase da demarcação. 
A escolha tambem deverá ser feita a aprasimento das partes, que se louvarão num só profissional, que será o agrimensor nomeado, ou em diversos profissionaes, para dentre eles ser escolhido o agrimensor. Nesta hipotese, será nomeado agrimensor o profissional indicado pela maioria. $\mathbf{E}$ essa maioria não será calculada pelo numero de litigantes, mas por um processo analogo ao da distribuição proporcional das custas nessas ações de demarcação; a metade correspondente ao proprietario do imovel demarcando e a outra metade é distribuida entre todos os confinantes, na proporção de suas testadas.

Os trabalhos tecnicos serão feitos exclusivamente pelo agrimensor, que entregará em cartorio a planta do imovel demarcando, acompanhada do memorial descritivo da demarcação e da respetiva caderneta das operações de campo.

Ouvidos os interessdos, seguir-se-á a sentença, que homologará, ou não, os trabalhos tecnicos da demarcação.

As disposições referentes á fase executoria das ações de demarcação, para a simplificação desse processo, deveriam ser substituidas pelos seguintes dispositivos:

Art. - Passada em julgado a sentença definitiva, mandando proceder a demarcação, serão intimados todos os interessados, demarcante e confrontantes, nas pessoas dos seus procuradores, ou mediante pregão em audiencia, quando não tiverem procuradores, ou estes não forem encontrados na séde do Juizo, para a escolha de um agrimensor, que execute todos os trabalhos tecnicos de demarcação, sob sua exclusiva responsabilidade.

Art. - Na audiencia, em que forem acusadas essas citações, proceder-se-á á escolha do agrimensor. Se todos os interessados indicarem um mesmo profissional, o juiz homologará a escolha das partes. Se forem diversos os indicados, o Juiz nomeará para servir de agrimensor o profissional que fôr indicado pela maioria. A maioria será calculada, não pelo numero de interessados, mas na proporção das suas testadas, correspondendo metade ao demarcante e sendo a outra metade distribuida entre todos os confinantes. 
Havendo empate, decidirá a sorte. A deliberação dos presentes á louvação obrigará aos ausentes.

Art. - Compromissado o agrimensor, o juiz designará dia para o inicio da demarcação. Desse despacho serão intimados todos os interessados e o agrimensor.

Art. - No dia designado, o agrimensor dará inicio aos trabalhos tecnicos da demarcação. Tendo em vista a sentença definitiva, que mandou proceder á demarcação, e os esclarecimentos que julgar necessarios e lhe forem prestados por testemunhas e visinhos, o agrimensor: - a), determinará e assinalará o ponto de partida para a medição do perimetro do imovel demarcando, se a demarcação fôr total; ou da linha litigiosa entre as propriedades confinantes, se a demarcação fôr parcial; b) procederá ao levantamento e medição de todo esse perimetro, na primeira hipotese; ou da linha litigiosa, na segunda; c) calculará toda a extensão superficial do imovel, se a demarcação fôr total.

Art. - Terminados os trabalhos de campo, o agrimensor fará o levantamento da planta do imovel demarcando e organisará o memorial descritivo da demarcação.

Paragrafo unico - No levantamento da planta e na organisação do memorial descritivo serão observadas as mesmas regras previstas para os correspondentes trabalhos tecnicos das divisões, excetuadas as que se referem á divisão do imovel entre os condominos; e, com as modificações adequadas, quando se tratar de demarcação parcial.

Art. - Entregues, pelo agrimensor, em cartorio, a planta, o memorial descritivo da demarcação e a caderneta das operações de campo, o escrivão junta-los-á aos autos e fará conclusão destes ao juiz, que mandará dar vista ás partes, para dizerem de fato e de direito sobre o processado. $O$ demarcante terá o praso de dez dias e igual praso terão em comum todos os confinantes.

Art. - Aplicam-se ás reclamações do demarcante, ou dos confinantes, o disposto relativamente ás reclamações do promovente, ou dos promovidos, nas divisões. 
Art. - Ouvidas as partes e preliminarmente decididas as suas reclamações, selados e preparados os autos, o Juiz proferirá a sua sentença, homologando, ou não, a demarcação.

\section{Divisões e demarcações amigaveis.}

Entre as inovações felizes do projeto do eminente Sr. Ministro Artur Ribeiro, se destacam as disposições referentes ás divisões e demarcações amigaveis.

Se todos os interessados são acordes, a fase contenciosa dessas ações pode ser substituida com vantagem pelo acôrdo das partes, judicialmente homologado. Assim homologado, esse acôrdo produzirá todos os efeitos da sentença definitiva proferida na fase contenciosa dessas ações.

0 que não se justifica, entretanto, é que os serviços tecnicos possam ser confiados a um pratico e que nesses trabalhos tecnicos sejam dispensadas formalidades importantes, imprescindiveis para que as respetivas plantas possam sem incorporadas á planta geral cadastral.

Seria conveniente a substituição do artigo 34 do Titulo referente aos processos de divisão e demarcação de terras pelas seguintes disposições:

Art. - Acordando as partes, as divisões e demarcações de terras poderão ser feitas amigavelmente, observadas as disposições dos artigos seguintes.

Art. - A petição inicial da ação de divisão amigavel deverá ser assinada por todos os condominos e conter os seguintes requisitos:

1. ${ }^{\circ}$ Os nomes e domicilios de todos os condominos e dos representantes legitimos dos incapazes.

2.) A designação da propriedade comum, pela sua denominação, situação e caracteristicos.

3.') A descrição dos seus limites, de acôrdo com os titulos que os constituiram. 
4..$^{\circ}$ A declaração de serem os terrenos compreendidos dentro do perimetro do imovel dividendo de uma mesma qualidade ou categoria, ou de categorias diferentes.

5.') O valor, por hectare, desses terrenos, ou dos terrenos compreendidos em cada uma dessas categorias.

6. ${ }^{\circ}$ A descrição das bemfeitorias comuns, existentes no imovel, com os respetivos valores.

7. ) A causa ou origem da comunhão.

8. ) A situação precisa das moradas e bemfeitorias, pertencentes a cada um dos condominos, existentes no imovel, com os seus valores.

9..$^{\circ}$ A declaração da quota abstrata, que compete a cada um dos condominos, no imovel dividendo.

10. ) O plano de divisão do imovel e constituição dos quinhões de todos os condominos, com a indicação precisa do logar em que devem ser localisados todos esses quinhões.

11. ) A escolha de um profissional, para servir de agrimensor, que deverá executar a divisão, sob a sua exclusiva responsabilidade.

12. ) Os honorarios do agrimensor.

13. ) A responsabilidade pelo pagamento dos honorarios do agrimensor e demais despezas da divisão, na proporção dos respectivos quinhões, se doutra forma não fôr expressamente convencionado.

14. ) A declaração ou estimativa do valor da causa.

Paragrafo unico - Esta petição deverá ser instruida com os titulos de dominio de todas os condominos e com o contrato feito com o agrimensor.

Art. - A petição inicial da ação de demarcação amigavel, total ou parcial, deverá ser assinada por todos os interessados, demarcante e confrontantes, e conter os seguintes requisitos:

1.') Os nomes e domicilios de todos os interessados, demarcante e confrontantes, e dos representantes legitimos dos incapazes.

2. ) A designação do imovel demarcando, pela sua denominação, situação e caracteristicos. 
3. ${ }^{\circ}$ A descrição minuciosa dos limites do imovel demarcando, que tem de ser constituidos ou aviventados, de acôrdo com os titulos das partes, ou em conformidade com o que nessa petição expressamente convencionarem.

$\left.4 .^{\circ}\right)$ A escolha do agrimensor, que deverá executar os trabalhos tecnicos da demarcação, sob sua exclusiva responsabilidade.

5. ${ }^{\circ}$ Os honorarios do agrimensor.

6. ${ }^{\circ}$ A responsabilidade pelo pagamento dos honorarios do agrimensor e demais despezas da demarcação, devendo ser a metade rateiada entre os outros interessados, proprietarios dos imoveis confinantes, na proporção de suas testadas, se doutra fórma não fôr expressamente convencionado.

7.') A declaração ou estimativa do valor da causa.

$\S$ Unico - Esta petição deverá ser instruida com o titulo de dominio do proprietario do imovel demarcando e, sendo possivel, com os dos confinantes; salvo, tratando-se de demarcação de terras devolutas. $\mathrm{E}$, em qualquer hipotese, com o contrato feito com o agrimensor.

Art. - $\mathrm{O}$ acôrdo das partes será tomado por termo, assinado por todos os interessados, ou seus representantes legaes, e homologado pelo juiz.

Art. - Depois que transitar em julgado a sentença homologatoria do acôrdo e tomado por termo o compromisso do agrimensor, o juiz designará dia para o inicio dos trabalhos tecnicos da divisão ou demarcação.

Art. - Nos trabalhos tecnicos das divisões e demarcações amigaveis, serão observadas as mesmas regras prescritas para identicos trabalhos nas correspondentes ações judiciais.

Art. - Entregues, em cartorio, pelo agrimensor, a planta, o memorial descritivo da divisão ou demarcação e a caderneta das operações de campo, sobre as mesmas dirão os interessados no prazo comum de dez dias. $O$ silencio de qualquer dos interessados equivale a sua aquiescencia aos trabalhos tecnicos. 
Art. - Se houver menores ou incapazes, será tambem ouvido o representante do Ministerio Publico.

- Art. - Se todos os interessados estiverem de acôrdo com os trabalhos tecnicos, ou julgadas improcedentes as arguições suscitadas por qualquer deles, o juiz homologará a divisão ou demarcação.

Art. - As disposições dos artigos anteriores podem ser aplicadas ás divisões e demarcações já iniciadas, se nisso convencionarem todos os interessados.

\section{Exigencia de profissional habilitado para o exercicio das funções de agrimensor.}

Regulamentada a profissão do agrimensor, pelo Decreto n. 23.569 de 11 de Dezembro de 1933, não se justifica a escolha de um pratico, sem as necessarias habilitações, para exercer as funções de agrimensor.

Ao tempo em que foi publicado o Decreto n. 1.241 de 3 de Janeiro de 1891, autorisando a nomeação, para servir de agrimensor, de qualquer pesisoa da escolha das partes, ainda se justificava essa providencia. Ha quasi meio seculo, era ainda deficiente o numero de agrimensores competentes e diplomados. Atualmente, em vez de carencia, a super abundancia de profissionais, tornando-se desnecessaria aquela exceção, que sómente era tolerada nos logares onde não existiam profissionais. Basta que se permita a escolha de profissionais, que não residam no fôro da causa.

Convem restaurar a disposição contida no artigo 49 do Decreto n. 720 de 5 de Setembro de 1890:

Art. - Somente poderão ser empregados como agrimensores, nas divisões e demarcações, judiciaes ou amigaveis, sob pena de nulidade do respetivo processo, os profissionaes habilitados na fórma do Decreto n. 23.569 de 11 de Dezembro de 1933. 
IX. Representação das partes, nas divisões e demarcações, judiciaes ou amigaveis, por advogados for= mados ou provisionados.

Os mesmos motivos, acima invocados, justificam a exigencia da representação das partes, em todas as ações de divisão ou demarcação, judiciaes ou amigaveis, por advogados formados ou provisionados.

Art. - Nas ações de divisão e demarcação de terras, judiciaes ou amigaveis, as partes serão representadas por advogados ou provisionados, habilitados na fórma do Decreto $\mathrm{n}$. 22.478 de 20 de Fevereiro de 1933.

Nas divisões e demarcações amigaveis, esses advogados ou provisionados deverão estar investidos de poderes especiaes e expressos para transigir.

\section{Conclusão.}

Convidado para representar, juntamente com os meus ilustrados colegas, os Exmos. Srs. Desembargadores José Barnabé de Mesquita e José Otilio da Gama, a Côrte de Apelação do Estado de Mato Grosso, da qual tive a honra de fazer parte durante quasi cinco lustros, no Congresso Nacional de Direito Judiciario, aceitei com justificado desvanecimento tão honroso mandato, com o proposito de contribuir com os meus fraços esforços para a elaboração dos nossos codigos processuaes, - a primeira etapa para a realisação, em futuro proximo, da unidade do Poder Judiciario.

Escolhi para assunto das minhas despretenciosas sugestões o processo das ações de divisão e demarcação de terras. $\mathrm{O}$ retalhamento dos grandes condominios em pequenas glebas e a liquidação de todas as duvidas quanto aos seus limites são problemas de grande alcance social. 
As sugestões acima expostas visam facilitar as divisões e demarcações, reduzindo as despezas que essas ações acarretam, suprimindo para esse fim as formalidades desnecessarias e despendiosas.

Com a redução dessas formalidades, não são entretanto sacrificadas as garantias dos direitos das partes, salvaguardados pelas formalidades indispensaveis, que foram mantidas para serem escrupulosamente observadas.

Com essas susgestões, pretendo apenas chamar a atenção dos competentes para o assunto. Grande foi a contribuição do Exmo. Sr. Ministro Artur Ribeiro, o ilustrado jurisconsulto e excelso juiz, ha pouco desaparecido, com o seu brilhantissimo trabalho, que não desmente e antes confirma os seus elevados merecimentos, anteriormente demonstrados na confecção do Projeto de Codigo de Processo Civil e Comercial de Minas Geraes. Muito ainda se espera da colaboração deste Congresso Nacional de Direito Judiciario, que, nesta data, se reune nesta Capital, convocado por uma feliz iniciativa do Instituto da Ordem dos Advogados Brasileiros.

Rio, 15 de Junho de 1936. 